\title{
Brown Adipose Tissue Has Sympathetic-Sensory Feedback Circuits
}

\author{
담aly Ryu, John T. Garretson, Yang Liu, Cheryl H. Vaughan, and Timothy J. Bartness \\ Department of Biology, Center for Obesity Reversal, Neuroscience Institute, Georgia State University, Atlanta, Georgia, 30302-4010
}

\begin{abstract}
Brown adipose tissue (BAT) is an important source of thermogenesis which is nearly exclusively dependent on its sympathetic nervous system (SNS) innervation. We previously demonstrated the SNS outflow from brain to BAT using the retrograde SNS-specific transneuronal viral tract tracer, pseudorabies virus (PRV152) and demonstrated the sensory system (SS) inflow from BAT to brain using the anterograde SS-specific transneuronal viral tract tracer, H129 strain of herpes simplex virus-1. Several brain areas were part of both the SNS outflow to, and receive SS inflow from, interscapular BAT (IBAT) in these separate studies suggesting SNS-SS feedback loops. Therefore, we tested whether individual neurons participated in SNS-SS crosstalk by injecting both PRV152 and H129 into IBAT of Siberian hamsters. To define which dorsal root ganglia (DRG) are activated by BAT SNS stimulation, indicated by c-Fos immunoreactivity (IR), we prelabeled IBAT DRG innervating neurons by injecting the retrograde tracer Fast Blue (FB) followed 1 week later by intra-BAT injections of the specific $\beta_{3}$-adrenoceptor agonist CL316,243 in one pad and the vehicle in the contralateral pad. There were PRV152 + H129 dually infected neurons across the neuroaxis with highest densities in the raphe pallidus nucleus, nucleus of the solitary tract, periaqueductal gray, hypothalamic paraventricular nucleus, and medial preoptic area, sites strongly implicated in the control of BAT thermogenesis. CL316,243 significantly increased IBAT temperature, afferent nerve activity, and c-Fos-IR in C2-C4 DRG neurons ipsilateral to the CL316,243 injections versus the contralateral side. The neuroanatomical reality of the SNS-SS feedback loops suggests coordinated and/or multiple redundant control of BAT thermogenesis.
\end{abstract}

Key words: c-Fos; electrophysiology; herpes simplex virus-1; pseudorabies virus; Siberian hamster; thermogenesis

\section{Introduction}

Brown adipose tissue (BAT) is a critical for nonshivering thermogenesis in rodents and its physiological function is directly controlled by its sympathetic nervous system (SNS) innervation (Bartness et al., 2010b; Richard and Picard, 2011). Rodent BAT has parasympathetic nervous system (PSNS) innervation of two minor BAT depot, pericardial (Schäfer et al., 1998) and mediastinal (Giordano et al., 2004), but not interscapular BAT (IBAT), the major rodent BAT depot (Giordano et al., 2004). Absence of BAT PSNS permits use of the viral transneuronal tracer pseudorabies virus (PRV; Bartha's K strain) to define the origins of the SNS outflow innervating peripheral tissues (for review, see Enquist, 2002; Song et al., 2005a), including IBAT (Bamshad et al., 1999; Oldfield et al., 2002). Increases in BAT SNS drive lead to release of norepinephrine (NE) from its SNS postganglionic nerve terminals thereby stimulating brown adipocyte $\beta_{3}$ adrenoceptors (Zhao et al., 1994) that ultimately activate uncoupling protein-1 resulting in thermogenesis increases (for review,

\footnotetext{
Received Aug. 8, 2014; revised Dec. 17, 2014; accepted Dec. 19, 2014.

Author contributions: V.R. and T.J.B. designed research; V.R., J.T.G., Y.L., and C.H.V. performed research; V.R., J.T.G., and Y.L. analyzed data; V.R. and T.J.B. wrote the paper.

This work was supported by the National Institutes of Health Research Grant R01 DK078358 to T.J.B. We thank the Department of Animal Resources staff at Georgia State University for attending to the health of our research animals. The authors declare no competing financial interests.

Correspondence should be addressed to Timothy J. Bartness, Department of Biology, Georgia State University, 24 Peachtree Center Avenue, Atlanta, GA 30302-4010. E-mail: bartness@gsu.edu.

DOI:10.1523/JNEUROSCI.3306-14.2015

Copyright $\odot 2015$ the authors $\quad 0270-6474 / 15 / 352181-10 \$ 15.00 / 0$
}

see Cannon and Nedergaard, 2004). This NE effect is mimicked by CL316,243, a highly selective $\beta_{3}$-adrenoceptor agonist both in vivo (Himms-Hagen et al., 1994; Atgie et al., 1998) and in vitro (Gabaldón et al., 1998).

BAT also has sensory system (SS) innervation. At the tissue level, IBAT has immunoreactivity (IR) for two proven SS neuropeptides, substance $\mathrm{P}$ and calcitonin gene-related peptide (Norman et al., 1988; De Matteis et al., 1998). Furthermore, with intra-IBAT injection of an anterograde transneuronal viral tract tracer, the H129 strain of herpes simplex virus 1 (HSV-1), we identified the central SS circuits from this tissue (Vaughan and Bartness, 2012). Many of the sites receiving SS input from IBAT (Vaughan and Bartness, 2012) also are part of the SNS outflow from the CNS to IBAT revealed by our PRV studies (Bamshad et al., 1999; Song et al., 2008). Thus, this SNS-SS overlap between studies suggests the possibility of individual neurons that are part of the SNS outflow from brain to BAT that also receive SS input from the tissue; that is, potential SNS-SS feedback loops serving an anatomical basis for crosstalk between BAT SNS and SS innervations. Although the exact role of the BAT SS is unknown, the impairment of the thermogenic response of BAT to acute cold exposure due to sensory denervation accomplished via intraIBAT injection of the sensory-specific neurotoxin capsaicin (Jancśo et al., 1980, 1985), strongly suggests BAT SS innervation is necessary for its optimal physiological functioning (Vaughan and Bartness, 2012). Therefore, we hypothesized that BAT SNS-SS feedback loops might exist and tested this, as well as 
identifying which dorsal root ganglia (DRG) receive sensory input when IBAT is adrenergically activated by: (1) injecting both the SS-specific transneuronal tract tracer, H129, and the SNSspecific transneuronal tract tracer, PRV, intra-IBAT to test for dually infected SNS-SS neurons; (2) injecting CL316,243 intraIBAT using c-Fos-IR to reveal activation (Hoffman et al., 1993) of pseudounipolar neurons within the DRG prelabeled with Fast Blue (FB), thereby identifying IBAT afferent neurons activated by IBAT adrenergic stimulation; and (3) measuring IBAT sensory nerve activity electrophysiologically after intra-IBAT CL316,243 injection.

\section{Materials and Methods}

In this study, we used Siberian hamsters (Phodopus sungorus) because these animals provide an irreplaceable model over other rodent models to study the development of a profound ( $\sim 50 \%$ body fat) naturally occurring seasonal obesity and its reversal ( $\sim 20 \%$ body fat). Using this model, we established the origins of the efferent sympathetic (SNS) outflow from brain to white adipose tissue (WAT) and BAT pads using SNS-specific viral tract tracer PRV152. Moreover, we identified the central sensory centers innervating those fat pads using sensory-specific viral tract tracer H129, which altogether prepared neuroanatomical background for identification of SNS-SS circuits to characterize specific fat pads. It should be noted that we have never noticed significant species differences in any neuroanatomical findings between Siberian hamsters, laboratory rats, and more recently laboratory mice; that is, they are more similar than different.

Animals. Adult male Siberian hamsters (Phodopus sungorus; $~ 3-$ to 4-months-old) from our breeding colony were single-housed in a long day photoperiod $\left(16 / 8 \mathrm{~h} \mathrm{light/dark} \mathrm{cycle;} \mathrm{at} 22 \pm 2^{\circ} \mathrm{C}\right)$ with ad libitum access to water and regular chow for 1 week before viral injections. All procedures were approved by the Georgia State University Institutional Animal Care and Use Committee and are in accordance with Public Health Service and United States Department of Agriculture guidelines.

Experiment 1: viral injections. All virus injections were performed according to Biosafety Level 2 standards. Hamsters $(n=8)$ were anesthetized with isoflurane (2.0-3.0\% in oxygen; Baxter Healthcare) and the left IBAT pad was exposed for a series of PRV152 (gift from Dr Enquist, Princeton University) microinjections $\left(7.5 \times 10^{7} \mathrm{pfu} / \mathrm{ml}\right)$ into five loci (150 nl/locus) evenly distributed across one IBAT pad. After $24 \mathrm{~h}$, the same IBAT pad received five H129 (gift from Dr Richard Dix, Georgia State University) microinjections $\left(7.5 \times 10^{7} \mathrm{pfu} / \mathrm{ml} ; 150 \mathrm{nl} /\right.$ locus $)$. The syringe was held in place for $1 \mathrm{~min}$ to prevent efflux of virus after each injection. Finally, the incision was closed with sterile sutures and wound clips. Nitrofurozone powder (nfz Puffer; Hess \& Clark) was applied locally to minimize the risk of bacterial infection. Note that previously we demonstrated that surgical isolation of the fat pad from the surrounding tissues before $\mathrm{H} 129$ injections results in a pattern of infection indistinguishable from that of pads injected in their natural in situ position suggesting the infections came directly from sensory nerves innervating the fat pad, but not the surrounding tissues (C. K. Song and T. J. Bartness, unpublished observations). As a control for possible viral diffusion, we also demonstrated that the same virus titer of PRV152 or of H129 and volume placed on the surface of the exposed IBAT pad resulted in no infection in the sympathetic ganglia or DRG, spinal cord, and brain as opposed to intra-IBAT pad viral infections (V. Ryu and T. J. Bartness, unpublished observations). In addition, we found both PRV152- and H129-infected neurons in the intermediolateral cell column (IML) of the spinal cords (data not shown), respectively, suggesting specific IBATSNS ganglia and IBAT-SS DRG-spinal cord-brain routes of infection, which are in concordance with our previous findings where PRV152 and H129 individually infected the classic SNS and SS spinal cord neurons (Bamshad et al., 1999; Vaughan and Bartness, 2012). Finally, we have not noticed left-right pad differences in brain infections with injections of either PRV152 or H129. Note that pilot studies indicated no left-right IBAT differences (C. H. Vaughan and T. J. Bartness; and C. K. Song and T. J. Bartness, unpublished observations) nor in our published work
(Bamshad et al., 1999; Song et al., 2008; Leitner and Bartness, 2009; Vaughan and Bartness, 2012).

Experiment 2: FB labeling and CL316,243 administration. One week before CL316,243 microinjections, Siberian hamsters $(n=12)$ were deeply anesthetized with ketamine/xylazine (100 mg/kg, $10 \mathrm{mg} / \mathrm{kg}$, i.p.) and a dorsal $2 \mathrm{~cm}$ interscapular incision was made to expose IBAT. The retrograde tracer FB (1.0\%; EMS-CHEMIE GmbH, Gross-Umstadt) was injected with a microsyringe into five separate loci ( $1 \mu \mathrm{l} /$ locus $)$ of the left IBAT. After the last injection, the incision was closed with sterile wound clips and ketofen (5 mg/kg, s.c.; Fort Dodge Animal Health) was administered for $3 \mathrm{~d}$ postinjection to minimize postoperative discomfort.

For CL316,243 administration, two electronic transponders (Bio Medic Data Systems) each with a built-in temperature sensor were gently implanted under each IBAT pad, the output of which was read with a handheld DAS-7007R scanner (Bio Medic Data Systems) for IBAT temperature $\left(\mathrm{T}_{\mathrm{IBAT}}\right)$ acquisition as we have used successfully previously (Brito et al., 2007; Nautiyal et al., 2008; Song et al., 2008; Leitner and Bartness, 2009; Vaughan et al., 2011; Vaughan and Bartness, 2012). This system provides an opportunity to program the transponder with a unique identification code to distinguish between left and right IBAT pad temperatures. Core body temperature $\left(\mathrm{T}_{\mathrm{b}}\right)$ in these anesthetized animals was measured using a rectal temperature sensor connected to BAT-10 Thermometer (Physitemp Instruments). CL316,243 (0.2 ng/kg in 0.9\% saline), a highly selective $\beta_{3}$-adrenoceptor agonist that stimulates facultative thermogenesis (Himms-Hagen et al., 1994), was injected intra-left IBAT at five loci $(2 \mu \mathrm{l} /$ locus for a total of $10 \mu \mathrm{l})$ while nearly simultaneous intra-right IBAT injections of the saline vehicle $(2 \mu \mathrm{l} /$ locus for a total of $10 \mu \mathrm{l})$ served as a within-animal control. In preliminary studies, we determined that subcutaneous CL316,243 injections at $0.2 \mathrm{ng} / \mathrm{kg}$ failed to elevate $\mathrm{T}_{\text {IBAT }}$ and therefore this dose was selected for IBAT microinjections (V. Ryu and T. J. Bartness, unpublished observations). Following each injection, the microsyringe needle was held in place for at least $1 \mathrm{~min}$ to minimize efflux. The incision was immediately closed with sterile wound clips and parallel temperature recordings from both IBAT pads, as well as $\mathrm{T}_{\mathrm{b}}$ were monitored every $5 \mathrm{~min}$ for $1 \mathrm{~h}$ postinjection (observation time based on pilot studies showing little, or most often, no change in temperatures after that time (V. Ryu and T. J. Bartness, unpublished observations).

Histology. Animals were terminated $6 \mathrm{~d}$ after the last PRV152 injections ( $5 \mathrm{~d}$ after the last H129 injections) based on progression of both viruses to the brain in pilot studies (V. Ryu and T. J. Bartness, unpublished observations). Hamsters were overdosed with pentobarbital sodium (Sleep Away; $300 \mathrm{mg} / \mathrm{kg}$ ) and transcardially perfused with $0.9 \%$ heparinized saline followed by $4.0 \%$ paraformaldehyde in $0.1 \mathrm{M} \mathrm{PBS,} \mathrm{pH}$ 7.4. The brains were collected and postfixed in the same fixative for 3-4 $\mathrm{h}$ at $4^{\circ} \mathrm{C}$, then transferred to a $30.0 \%$ sucrose solution in $0.1 \mathrm{M}$ PBS with $0.1 \%$ sodium azide and stored at $4^{\circ} \mathrm{C}$ until they were sectioned on a freezing stage sliding microtome at $30 \mu \mathrm{m}$. Sections were stored in 0.1 M PBS solution with $0.1 \%$ sodium azide until processed for double immunofluorescence.

For the CL316,243 experiment, the hamsters were killed with pentobarbital sodium (Sleep Away; $300 \mathrm{mg} / \mathrm{kg}$ ) immediately after individual temperature recordings and transcardially perfused (see above). DRG associated with vertebral levels $\mathrm{C} 1-\mathrm{T} 5$ were extracted bilaterally, the epineurium debrided from the ganglia, postfixed in the same fixative for $15 \mathrm{~min}$ and transferred to an $18.0 \%$ sucrose solution in $0.1 \mathrm{M}$ PBS with $0.1 \%$ sodium azide at $4^{\circ} \mathrm{C}$ overnight. DRG were sectioned longitudinally at $20 \mu \mathrm{m}$ and directly mounted onto slides (Superfrost Plus, VWR International) in three series with every fourth section on the same slide. This procedure yielded $\sim 24$ sections with each slide containing eight sections. Therefore, multiplying the number per section by 24 will give an estimated total neuronal number per ganglion.

For the double-label fluorescent immunohistochemistry, free-floating brain sections were rinsed in $0.1 \mathrm{M}$ PBS $(2 \times 15 \mathrm{~min})$ followed by a $30 \mathrm{~min}$ blocking in $10.0 \%$ normal goat serum (NGS; Vector Laboratories) and $0.4 \%$ Triton X-100 in 0.1 M PBS. Next, sections were incubated with a mixture of primary rabbit anti-HSV-1 antibody (1:2000; Dako Cytomation) and mouse anti-GFP antibody (1:700; Abcam) for $18 \mathrm{~h}$. Sections were then incubated in the mixture of the secondary goat anti-rabbit 
(1:700; Jackson ImmunoResearch) and goat anti-mouse AlexaFluor 488 (1:700; Jackson ImmunoResearch) antibodies with $2.0 \%$ NGS and $0.4 \%$ Triton X-100 in $0.1 \mathrm{M}$ PBS for $2 \mathrm{~h}$ at room temperature. For immunohistochemical controls, the primary antibody was either omitted or preadsorbed with the immunizing peptide overnight at $4^{\circ} \mathrm{C}$ resulting in no immunoreactive staining. Sections were mounted onto slides (Superfrost Plus) and coverslipped using ProLong Gold Antifade Reagent (Life Technologies).

After rehydration, DRG sections were processed for detection of $\mathrm{H} 129$ (anti-HSV-1 antibody, 1:100 dilution; Dako Cytomation,) and PRV152 (anti-GFP antibody, 1:500 dilution; Abcam) directly on the slides using the same immunohistochemical protocol as above.

For DRG c-Fos immunostaining on the slides, sections were rinsed in $0.1 \mathrm{~m}$ PBS $(2 \times 15 \mathrm{~min})$ followed by $1 \mathrm{~h}$ blocking in $5.0 \%$ normal horse serum (NHS; Vector Laboratories) and $0.3 \%$ Triton X-100 in $0.1 \mathrm{M}$ PBS. Sections were then incubated in the primary rabbit anti-c-Fos (1:500; sc-52; Santa Cruz Biotechnology) antibody with $10.0 \%$ NHS and $0.3 \%$ Triton X-100 in 0.1 M PBS overnight. Next, the sections were incubated in the secondary donkey anti-rabbit Cy3 (1:200; Jackson ImmunoResearch) for $3 \mathrm{~h}$, rinsed with $0.1 \mathrm{M}$ PBS $(3 \times 15 \mathrm{~min})$ and coverslipped with ProLong Gold Antifade Reagent (Life Technologies). All steps were performed at room temperature.

Experiment 3: electrophysiological recordings of IBAT afferent nerve activity. Siberian hamsters $(n=10)$ were anesthetized with ketamine/xylazine $(100 \mathrm{mg} / \mathrm{kg}, 10 \mathrm{mg} / \mathrm{kg}$, i.p.), a $2 \mathrm{~cm}$ dorsal interscapular incision made, IBAT and connective tissue resected exposing nerves innervating right IBAT lobe. Single nerves were isolated with a petroleum jelly barrier, severed, and then the decentralized nerve placed on silver (32 guage) hook electrodes to measure afferent activity. A petroleum jelly mineral oil mixture (1:1) was applied to the site completely enveloping the electrode/ nerve connection, and then warm mineral oil was pooled into the recording area to insulate electrical noise, secure the nerve on the electrode, and reduce drying of tissue. A steady anesthetic plane was maintained with supplemental ketamine by examining toe pinch repeatedly on all four paws and testing the eye blink response throughout the recording. Three stainless steel needles connected with SILASTIC tubing to microsyringes affixed to a microsyringe infusion pump were inserted into right IBAT along the lateral-coronal plane spaced $4-5 \mathrm{~mm}$ apart at a depth of $4 \mathrm{~mm}$ each. In a pilot experiment, we used this delivery system for intra-IBAT application of Evan's blue dye as a visual surrogate for CL316,243 and found that the whole ventral IBAT pad turned blue showing excellent distribution of fluid across the pad by this method (J. T. Garretson and T. J. Bartness, unpublished observations). Ten minutes of basal electrical activity was measured and served as baseline. At that point, $15 \mu \mathrm{l}$ of CL316,243 $(0.2 \mathrm{ng} / \mathrm{kg})$ or the saline vehicle was infused at a rate of 3.0 $\mu \mathrm{l} / \mathrm{min}$ and recording continued.

Extracellular signals were amplified 10k times with a differential AC amplifier set to low pass filter $100 \mathrm{~Hz}$ and high pass filter $1000 \mathrm{~Hz}$ (Model 1700 , A-M Systems). The analog signal was visualized using an oscilloscope (2530, BK Precision) to optimize signal-to-noise ratio and concurrently identified via an audio analyzer (74-30-1, FHC). Data were digitized through Digidata 1440a data acquisition system (1440a; Molecular Devices), recorded with accompanying Clampex 10.3 software at a $20,000 \mathrm{~Hz}$ sampling rate, then analyzed for number of spikes based on a voltage threshold two SDs above mean nonsignal noise via the Clampfit 10.2 data analysis software package. All identified waveforms were visually screened whereby any aberrant signals counted by the software were easily identified and removed from the analyses.

Quantitative and statistical analysis. Images were viewed and captured using $100 \times$ and $200 \times$ magnification with an Olympus DP73 imaging photomicroscope with appropriate filters for $\mathrm{Cy} 3$ and Alexa Fluor 488. The single-labeled PRV152 and H129, c-Fos, and FB images were evaluated and overlaid with the aid of CellSens (Olympus) and the Adobe Photoshop CS5 software. In every sixth brain section, we counted cells showing SNS PRV152+SS H129-IR, single cells with PRV152- or H129-IR as well as c-Fos-IR and FB labeling in every forth DRG section using the manual tag feature of the Adobe Photoshop CS5 software thus eliminating the likelihood of counting the same neurons more than once. Absolute neuronal numbers, as well as their corresponding percentages in the brain and DRG, were averaged across each examined region/nucleus/ganglion from all animals. A mouse brain atlas (Paxinos and Franklin, 2007) was used to identify brain areas because no Siberian hamster brain atlas is available and because of the similarity in size and shape of most of the brain structures between Siberian hamsters and mice. For the preparation of the photomicrographs, we used Adobe Photoshop CS5 only to adjust the brightness, contrast, and sharpness, to remove artifactual obstacles (i.e., obscuring bubbles) and to make the composite plates.

Temperature data were analyzed by one-way repeated-measures ANOVA followed by Holm-Sidak's or Bonferroni's least significant difference post hoc tests using NCSS v2007. For electrophysiological analysis, spike number across time was quantified by collapsing the spikes into $10 \mathrm{~min}$ bins from the onset of infusion up to $20 \mathrm{~min}$ postinfusion. The percentage change of mean nerve activity from baseline was compared using a $2 \times 2$ analysis ANOVA (time $\times$ drug), and post hoc analysis of drug effects at individual time points using Student's $t$ test with Bonferroni's correction. Significance was set at $p<0.05$.

\section{Results}

Following viral infections, hamsters remained asymptomatic until Day 5 after PRV152 and Day 4 after H129 inoculation, whereupon many began to display some symptoms of infection including occasional slight loss of body weight and decreased mobility, but most often an ungroomed coat. All hamsters were killed the next day for histological analyses when such symptoms became apparent. Five of eight animals were equally infected by both PRV152 and H129 viral tracers throughout the neuroaxis from the hindbrain to the forebrain and therefore were included in the analyses. Three other animals exhibited overinfection of the CNS by either PRV152 and/or H129 indicated by widespread "cloudy plaques" around the overinfected neurons and were excluded from the analysis. We noticed both PRV152- and H129labeled (-infected) neurons in the IML of the spinal cord (data not shown) with the latter SS innervation of the IML in accordance with studies showing SS presence in the IML of amphibians (Horn and Stofer, 1989), prenatal laboratory mice (Funakoshi et al., 2003), laboratory rats (Peng et al., 1989; Yamamoto et al., 1989; Dun et al., 1996; Tan et al., 1996), and Djungarian (Siberian) hamsters (Reuss, 1993).

\section{Experiment 1: viral infections in the brain}

The dual injections of the SNS nerve tract tracer PRV152 and the SS nerve tract tracer H129 unilaterally into the same (left) IBAT pad appeared bilaterally in the brain with slightly ipsilateral domination to the side of inoculation for both viruses.

Both single- and double-labeled neurons were notably present in the hindbrain. Some of the hindbrain areas with the highest percentages of double-labeled PRV152- and H129-IR cells included the lateral paragigantocellular nucleus (LPGi; $13.0 \pm$ 1.2\%; Table 1), raphe obscurus nucleus (ROb; $12.9 \pm 1.4 \%$; Table 1 ; Fig. $1 A, B)$, medial parabrachial nucleus (MPB; $12.7 \pm$ $1.1 \%$; Table 1$)$, raphe pallidus nucleus (RPa; $12.6 \pm 1.1 \%$; Table 1; Fig. 1A), and superior vestibular nucleus (SuVe; $12.1 \pm 1.8 \%$; Table 1). The $\mathrm{RPa}$ and $\mathrm{ROb}$ also were among the regions with the highest absolute numbers of infected neurons (Table 1; Figs. $1 A, B, 2 A)$. Overall, the percentage of double-labeled hindbrain neurons was $\sim 10.0 \%$ (Fig. $2 B$ ).

The midbrain areas with the highest percentages of doublelabeled PRV152- and H129-IR cells were the lateral periaqueductal gray (LPAG; $11.5 \pm 2.1 \%$; Table 1 ) and ventrolateral periaqueductal gray (VLPAG; $10.3 \pm 1.8 \%$; Table 1$)$. Among the brain sites with a predominantly SNS efferent output to IBAT, compared with a SS afferent input from the same IBAT pad, were the $\operatorname{LPAG}\left(F_{(1,9)}=7.76, p<0.05\right.$; Table 1; Fig. 1C,D), dorsolat- 
Table 1. Distribution of sympathetic (PRV152) and sensory (H129) neurons across the neuroaxis

\begin{tabular}{|c|c|c|c|c|}
\hline & PRV152 & H129 & PRV152 + H129 & $\begin{array}{l}\text { Percentage of } \\
\text { PRV152 + H129 }\end{array}$ \\
\hline \multicolumn{5}{|l|}{ Hindbrain } \\
\hline $7 \mathrm{~N}$ & $67.4 \pm 12.1$ & $57.6 \pm 19.5$ & $11.8 \pm 3.0$ & $10.4 \pm 1.3$ \\
\hline $10 \mathrm{~N}$ & $16.0 \pm 8.2$ & $14.5 \pm 1.2$ & $2.0 \pm 1.6$ & $5.7 \pm 4.7$ \\
\hline $12 \mathrm{~N}$ & $24.3 \pm 5.2$ & $17.0 \pm 8.0$ & $0.7 \pm 0.3$ & $1.9 \pm 1.0$ \\
\hline $\mathrm{Pn} 0$ & $38.0 \pm 16.0$ & $27.4 \pm 9.6$ & $6.4 \pm 2.5$ & $11.3 \pm 1.1$ \\
\hline $\mathrm{PnC}$ & $51.4 \pm 15.1$ & $42.6 \pm 8.1$ & $9.2 \pm 2.5$ & $10.6 \pm 1.9$ \\
\hline SuVe & $74.2 \pm 20.8$ & $59.6 \pm 16.1$ & $13.2 \pm 2.4$ & $12.1 \pm 1.8$ \\
\hline MPB & $36.6 \pm 10.3$ & $40.5 \pm 8.4$ & $7.6 \pm 1.5$ & $12.7 \pm 1.1$ \\
\hline LPBI & $6.3 \pm 2.9$ & $5.3 \pm 1.6$ & $1.7 \pm 0.8$ & $7.3 \pm 4.7$ \\
\hline LPBC & $23.6 \pm 7.1$ & $13.4 \pm 5.3$ & $3.0 \pm 1.2$ & $9.5 \pm 4.3$ \\
\hline MPBE & $11.3 \pm 5.6$ & $11.3 \pm 4.7$ & $2.0 \pm 0.7$ & $8.0 \pm 2.6$ \\
\hline $\mathrm{LC}$ & $29.8 \pm 9.9$ & $28.3 \pm 5.7$ & $5.0 \pm 1.5$ & $8.5 \pm 2.4$ \\
\hline Bar & $16.3 \pm 6.6$ & $9.7 \pm 4.6$ & $3.8 \pm 1.2$ & $11.6 \pm 4.8$ \\
\hline $\operatorname{Pr} 5$ & $29.0 \pm 13.3$ & $26.8 \pm 9.6$ & $5.5 \pm 2.3$ & $11.3 \pm 0.8$ \\
\hline LDTg & $13.3 \pm 4.6$ & $4.3 \pm 0.7$ & $1.7 \pm 0.7$ & $12.3 \pm 7.0$ \\
\hline Mo5 & $18.7 \pm 3.3$ & $20.7 \pm 1.1$ & $3.7 \pm 0.5$ & $10.2 \pm 1.0$ \\
\hline $\mathrm{RMg}$ & $83.8 \pm 25.9$ & $87.2 \pm 17.7$ & $17.2 \pm 4.1$ & $11.4 \pm 1.2$ \\
\hline $\mathrm{RPa}$ & $159.2 \pm 34.0$ & $148.8 \pm 41.6$ & $36.2 \pm 9.2$ & $12.6 \pm 1.1$ \\
\hline ROb & $154.5 \pm 55.9$ & $116.0 \pm 14.1$ & $30.5 \pm 5.0$ & $12.9 \pm 1.4$ \\
\hline $\mathrm{Gi}$ & $52.8 \pm 28.8$ & $39.0 \pm 13.5$ & $6.2 \pm 3.0$ & $6.4 \pm 2.2$ \\
\hline LPGi & $31.0 \pm 6.6$ & $29.0 \pm 6.8$ & $7.0 \pm 1.3$ & $13.0 \pm 1.2$ \\
\hline DPGi & $42.0 \pm 17.3$ & $42.3 \pm 16.5$ & $7.3 \pm 2.8$ & $8.5 \pm 1.0$ \\
\hline GiV & $108.0 \pm 19.7$ & $127.2 \pm 32.4$ & $19.0 \pm 3.0$ & $9.2 \pm 1.0$ \\
\hline PCRt & $14.0 \pm 4.1$ & $10.7 \pm 3.9$ & $1.3 \pm 0.5$ & $4.6 \pm 2.0$ \\
\hline 10 & $152.7 \pm 41.6$ & $129.3 \pm 15.0$ & $25.7 \pm 6.1$ & $9.8 \pm 1.8$ \\
\hline LRt & $120.7 \pm 36.1$ & $96.0 \pm 24.0$ & $18.7 \pm 2.9$ & $9.4 \pm 1.0$ \\
\hline MdV & $59.3 \pm 39.9$ & $43.0 \pm 18.0$ & $9.0 \pm 5.9$ & $6.8 \pm 3.4$ \\
\hline NTS & $275.7 \pm 60.4$ & $201.2 \pm 58.9$ & $33.4 \pm 4.2$ & $7.3 \pm 1.4$ \\
\hline Solc & $28.3 \pm 5.2$ & $21.0 \pm 4.7$ & $5.2 \pm 1.1$ & $10.5 \pm 2.1$ \\
\hline Solce & $7.2 \pm 2.8$ & $5.3 \pm 2.0$ & $1.3 \pm 0.4$ & $9.3 \pm 2.6$ \\
\hline SolDL & $31.8 \pm 15.2$ & $27.9 \pm 14.8$ & $4.7 \pm 1.9$ & $7.7 \pm 1.7$ \\
\hline SolG & $21.7 \pm 10.9$ & $15.3 \pm 4.5$ & $2.8 \pm 0.4$ & $7.1 \pm 2.3$ \\
\hline Soll & $7.4 \pm 3.0$ & $4.8 \pm 1.5$ & $1.2 \pm 0.2$ & $9.3 \pm 3.1$ \\
\hline SollM & $25.3 \pm 8.8$ & $19.5 \pm 4.1$ & $3.7 \pm 1.3$ & $7.9 \pm 2.2$ \\
\hline SolM & $97.3 \pm 12.0$ & $66.0 \pm 14.5$ & $12.7 \pm 4.3$ & $7.2 \pm 2.0$ \\
\hline SolV & $11.7 \pm 3.4$ & $10.8 \pm 3.5$ & $2.0 \pm 0.2$ & $8.6 \pm 1.3$ \\
\hline SolVL & $45.8 \pm 18.3$ & $32.1 \pm 10.2$ & $6.0 \pm 2.8$ & $7.5 \pm 2.4$ \\
\hline Pr & $25.5 \pm 11.2$ & $15.0 \pm 6.6$ & $3.8 \pm 2.8$ & $6.2 \pm 3.1$ \\
\hline \multicolumn{5}{|l|}{ Midbrain } \\
\hline PAG & $260.6 \pm 51.3$ & $109.2 \pm 28.8$ & $32.0 \pm 5.8$ & $9.6 \pm 1.5$ \\
\hline DMPAG & $32.4 \pm 9.3$ & $12.2 \pm 4.7$ & $2.8 \pm 1.11$ & $6.3 \pm 1.2$ \\
\hline DLPAG & $26.0 \pm 6.1$ & $8.4 \pm 2.6^{*}$ & $1.8 \pm 0.7$ & $5.1 \pm 1.6$ \\
\hline LPAG & $60.0 \pm 11.5$ & $30.0 \pm 6.9^{*}$ & $8.8 \pm 1.3$ & $11.5 \pm 2.1$ \\
\hline VLPAG & $54.8 \pm 11.6$ & $18.2 \pm 6.0$ & $6.4 \pm 1.4$ & $10.3 \pm 1.8$ \\
\hline $\mathrm{DR}$ & $23.6 \pm 6.7$ & $7.0 \pm 2.2^{*}$ & $2.4 \pm 0.6$ & $7.7 \pm 2.4$ \\
\hline DpMe & $54.3 \pm 20.3$ & $19.0 \pm 6.4$ & $6.0 \pm 1.9$ & $8.5 \pm 3.1$ \\
\hline $\mathrm{R}$ & $18.0 \pm 5.5$ & $9.6 \pm 2.9$ & $2.6 \pm 0.2$ & $9.4 \pm 3.3$ \\
\hline VTA & $32.5 \pm 12.7$ & $13.5 \pm 4.6$ & $3.5 \pm 1.2$ & $7.6 \pm 2.8$ \\
\hline \multicolumn{5}{|l|}{ Forebrain } \\
\hline MPA & $79.8 \pm 8.9$ & $6.4 \pm 3.0^{*}$ & $2.2 \pm 1.0$ & $3.0 \pm 1.7$ \\
\hline MPO & $36.4 \pm 13.8$ & $6.8 \pm 2.6^{*}$ & $1.4 \pm 0.9$ & $5.0 \pm 3.0$ \\
\hline $\mathrm{MnPO}$ & $17.4 \pm 5.2$ & $0.8 \pm 0.8^{*}$ & $0.2 \pm 0.2$ & $2.0 \pm 2.0$ \\
\hline LPO & $23.8 \pm 10.5$ & $1.5 \pm 0.8$ & $0.8 \pm 0.4$ & $1.7 \pm 1.0$ \\
\hline AVPO & $32.6 \pm 9.5$ & $7.8 \pm 5.9$ & $1.4 \pm 1.0$ & $2.8 \pm 1.7$ \\
\hline AVPe & $23.5 \pm 7.9$ & $3.3 \pm 1.8$ & $1.3 \pm 0.8$ & $3.3 \pm 2.3$ \\
\hline SCh & $13.5 \pm 6.9$ & $4.5 \pm 1.7$ & $0.5 \pm 0.4$ & $1.2 \pm 1.0$ \\
\hline AHA & $7.4 \pm 2.2$ & $3.8 \pm 2.2$ & $1 \pm 0.4$ & $9.2 \pm 4.3$ \\
\hline AHP & $22.8 \pm 9.1$ & $9.8 \pm 5.5$ & $2.4 \pm 1.3$ & $5.8 \pm 2.4$ \\
\hline PVH & $277.4 \pm 55.5$ & $237.8 \pm 58.7$ & $48.8 \pm 8.7$ & $11.2 \pm 1.8$ \\
\hline PaAP & $15.0 \pm 4.9$ & $14.8 \pm 7.2$ & $3.5 \pm 1.7$ & $10.7 \pm 3.2$ \\
\hline $\mathrm{PaDC}$ & $30.6 \pm 7.3$ & $36.4 \pm 11.3$ & $6.2 \pm 1.7$ & $8.9 \pm 3.1$ \\
\hline PaMP & $137.8 \pm 22.1$ & $129.8 \pm 32.8$ & $23.6 \pm 4.2$ & $10.4 \pm 1.7$ \\
\hline PaMM & $12.2 \pm 4.9$ & $7.2 \pm 2.3$ & $1.8 \pm 1.1$ & $\begin{array}{c}6.8 \pm 4.5 \\
\text { (Table Continues) }\end{array}$ \\
\hline
\end{tabular}

Table 1. Continued

\begin{tabular}{lcccc}
\hline & PRV152 & H129 & PRV152 + H129 & $\begin{array}{c}\text { Percentage of } \\
\text { PRV152 }+ \text { H129 }\end{array}$ \\
\hline PaLM & $36.0 \pm 6.8$ & $35.3 \pm 10.7$ & $5.8 \pm 1.7$ & $8.5 \pm 1.4$ \\
PaV & $16.7 \pm 2.5$ & $16.3 \pm 4.2$ & $3.3 \pm 1.4$ & $12.6 \pm 5.8$ \\
PaP0 & $22.7 \pm 12.0$ & $25.4 \pm 12.5$ & $7.6 \pm 5.2$ & $8.4 \pm 2.3$ \\
Arc & $19.6 \pm 7.1$ & $8.2 \pm 2.1$ & $2.0 \pm 0.9$ & $5.9 \pm 2.6$ \\
LH & $101.6 \pm 20.8$ & $40.0 \pm 3.9$ & $11.8 \pm 1.7$ & $9.3 \pm 0.6$ \\
VMH & $6.4 \pm 4.1$ & 0 & 0 & 0 \\
DM & $83.3 \pm 31.8$ & $30.3 \pm 5.8$ & $8.7 \pm 1.7$ & $9.8 \pm 2.3$ \\
PH & $39.8 \pm 12.9$ & $15.8 \pm 1.5$ & $5.0 \pm 1.1$ & $11.1 \pm 1.5$ \\
Zl & $18 \pm 11.0$ & $8.6 \pm 4.5$ & $1.2 \pm 0.8$ & $2.6 \pm 1.7$ \\
SubZl & $31.6 \pm 4.6$ & $22.4 \pm 8.9$ & $6.8 \pm 2.0$ & $13.5 \pm 3.9$ \\
\hline
\end{tabular}

$7 \mathrm{~N}$, Facial nucleus; 10N, dorsal motor nucleus of the vagus nerve; 12N, hypoglossal nucleus; Arc, arcuate nucleus; AVPe, anteroventral periventricular nucleus; AVPO, anteroventral preoptic nucleus; Bar, Barrington's nucleus; GiV, gigantocellular reticular nucleus, ventral part; I0, inferior olive; LC, locus coeruleus; LDTg, laterodorsal tegmental nucleus; LPBC, lateral parabrachial nucleus, central part; LPBI, lateral parabrachial nucleus, internal part; LRt, lateral reticular nucleus; $\mathrm{MdV}$, medullary reticular nucleus, ventral part; $\mathrm{MnP0}$, median preoptic nucleus; $\mathrm{Mo5}$, motor trigeminal nucleus; MPBE, medial parabrachial nucleus external part; PaAP, paraventricular hypothalamic nucleus, anterior parvicellular part; $\mathrm{PaDC}$, paraventricular hypothalamic nucleus, dorsal cap; $\mathrm{PaLM}$, paraventricular hypothalamic nucleus, lateral magnocellular part; $P a M M$, paraventricular hypothalamic nucleus, medial magnocellular part; $\mathrm{PaP}$, paraventricular hypothalamic nucleus, posterior part; $\mathrm{PaV}$, paraventricular hypothalamic nucleus, ventral part; $\mathrm{PCRt}$, parvicellular reticular nucleus; $\mathrm{PH}$, posterior hypothalamic area; $\mathrm{PnC}$, pontine reticular nucleus, caudal part; $\mathrm{PnO}$, pontine reticular nucleus, oral part; Pr, prepositus nucleus; Pr5, principal sensory trigeminal nucleus; $\mathrm{R}$, red nucleus; $\mathrm{RMg}$, raphe magnus nucleus; $\mathrm{SCh}$, suprachiasmatic nucleus; SolC, nucleus of the solitary tract, commissural part; SolM, nucleus of the solitary tract, medial part; SolVL, nucleus of the solitary tract, ventrolateral part. Data are expressed as mean $\pm \operatorname{SEM}(n=5) ;{ }^{*} p<0.05$ versus PRV152.

eral periaqueductal gray $\left(\mathrm{DLPAG} ; F_{(1,9)}=42.91, p<0.05\right.$; Table 1 ; Fig. $1 C$ ), and dorsal raphe nucleus (DR; $F_{(1,9)}=5.35, p<0.05$; Table 1; Fig. 1C). As in the hindbrain, the overall percentage of midbrain double-labeled neurons was $\sim 10.0 \%$ (Fig. $2 B$ ).

In the posterior hypothalamus and thalamus of the forebrain, the areas with extensive percentages of double-infected neurons included the sub zona incerta (SubZI; $13.5 \pm 3.9 \%$; Table 1), posterior hypothalamic nucleus ( $\mathrm{PH} ; 11.1 \pm 1.5 \%$; Table 1$)$, dorsomedial hypothalamic nucleus (DM; $9.8 \pm 2.3 \%$; Table 1; Fig. $1 E, F)$, lateral hypothalamic area (LH; $9.3 \pm 0.6 \%$; Table 1; Fig. $1 G, H)$, paraventricular hypothalamic nucleus $(\mathrm{PVH} ; 11.2 \pm$ $1.8 \%$; Table 1; Fig. $1 I, J$ ), and anterior hypothalamic area (AHA; $9.2 \pm 4.3 \%$; Table 1 ). The infected neurons were more heavily represented in the medial parvicellular (PaMP) subnucleus within the PVH (absolute numbers: $137.8 \pm 22.1$ for PRV152-IR neurons and $129.8 \pm 32.8$ for H129-IR neurons; Table 1). The ventromedial hypothalamic nucleus (VMH) was scarcely represented only by a few PRV152-IR neurons by comparison with other forebrain regions (Table 1; Fig. 1G,I) as we have seen previously (Bamshad et al., 1999; Song et al., 2008; Leitner and Bartness, 2009). The overall percentage of PRV152- and H129-IR posterior hypothalamus and thalamus double-labeled neurons was $\sim 9.0 \%$ (Fig. $2 B$ ).

In the anterior hypothalamus of the forebrain, the medial preoptic area (MPA), medial preoptic nucleus (MPO), and median preoptic nucleus $(\mathrm{MnPO})$ had significantly higher absolute numbers of PRV152-IR neurons compared with those infected with $\mathrm{H} 129\left(F_{(1,9)}=60.88, p<0.05\right.$ for MPA; $F_{(1,9)}=5.67, p<$ 0.05 for MPO; and $F_{(1,9)}=9.81, p<0.05$ for MnPO; Table 1; Figs. $1 K, L, 2 B)$. The H129 immunostaining was suggestively decreased compared with PRV152 immunostaining in other forebrain areas such as the lateral preoptic area (LPO), anteroventral preoptic nucleus (AVPO) and anteroventral periventricular nucleus AVPe; $\left(F_{(1,9)}=3.96, p=0.081\right.$ for LPO; $F_{(1,9)}=4.89, p=$ 0.058 for AVPO; and $F_{(1,9)}=5.38, p=0.057$ for AVPe; Table 1 ). The percentage of anterior hypothalamus double-labeled neurons $(\sim 3.5 \%)$ was significantly lower than those in the posterior hypothalamus and thalamus, midbrain, and hind- 

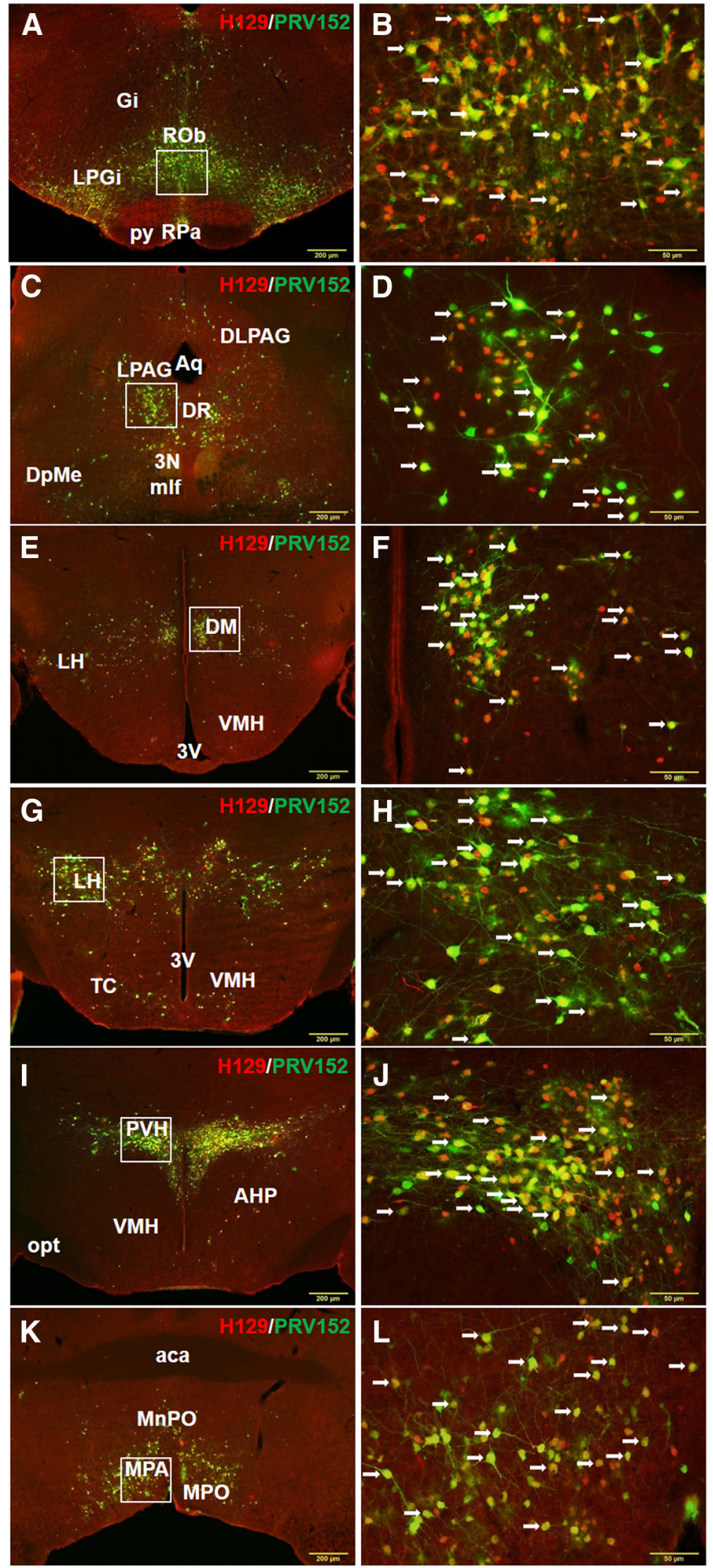

Figure 1. Low $(\boldsymbol{A})$ and high $(\boldsymbol{B})$ magnification of the microphotographs illustrating single PRV152 (green), single H129 (red), and double PRV152 + H129 (arrows) immunolabeling in the RPa and ROb following viral injections into IBAT. Gi, Gigantocellular reticular nucleus; py, pyramidal tract. $n=5$. Low $(\boldsymbol{C})$ and high $(\boldsymbol{D})$ magnification of the microphotographs illustrating single PRV152 (green), single H129 (red), and double PRV152 + H129 (arrows) immunolabeling in the PAG following viral injections into IBAT. 3N, Oculomotor nucleus; Aq, aqueduct; DpMe, deep mesencephalic nucleus; mlf, medial longitudinal fasciculus. Low $(\boldsymbol{E})$ and high $(\boldsymbol{F})$ magnification of the microphotographs illustrating single PRV152 (green), single H129 (red), and double PRV152 + H129 brain $\left(F_{(3,19)}=9.61, p<0.05\right.$; Fig. $\left.2 B\right)$, where there was no statistical difference between the numbers of PRV152/H129 colocalized neurons (Fig. 2B).

The RPa and nucleus of the solitary tract (NTS) of the hindbrain, the PAG of the midbrain, and the PVH of the forebrain contained the highest absolute numbers of both single- and doublelabeled virally infected neurons (Fig. 2A). The MPA of the forebrain had the highest absolute number only for PRV152 singlelabeled neurons $\left(F_{(1,9)}=60.88, p<0.05\right.$ vs H129; Fig. 2A).

Experiment 2: IBAT thermogenesis, DRG c-fos immunostaining of FBlabeled neurons after intra-IBAT

\section{CL316,243 administration}

One aim of this study was to test whether a highly selective $\beta_{3}$-adrenoceptor agonist, CL316,243, stimulated facultative thermogenesis in IBAT. Compared with saline vehicle-treated right IBAT, intra-left IBAT CL316,243 injections significantly increased $\mathrm{T}_{\text {IBAT }}$ within $10 \mathrm{~min}$ and this effect remained significant up to $60 \mathrm{~min}$ postinjections $\left(t_{(21)}=11.73, p<0.05\right.$; Fig. $3 A$ ). The difference in $\mathrm{T}_{\text {IBAT }}$ between CL316,243- and saline-treated fat pads steadily increased to $0.8^{\circ} \mathrm{C}$ by $10 \mathrm{~min}$, then slightly dropped to $0.56^{\circ} \mathrm{C}$ by $20 \mathrm{~min}$ and stabilized to $0.53^{\circ} \mathrm{C}$ by $60 \mathrm{~min}$ (Fig. $3 \mathrm{~B}$ ). $\mathrm{T}_{\mathrm{b}}$ did not undergo significant fluctuations over $60 \mathrm{~min}$; however, it was significantly lower compared with CL316,243induced temperature increases $\left(t_{(21)}=\right.$ 26.89, $p<0.05$; Fig. 3A).

To define which DRG were activated by BAT SNS stimulation, we prelabeled DRG neurons innervating IBAT by injecting a conventional retrograde tracer $\mathrm{FB}$ followed 1 week later by intra-IBAT injections of $\beta_{3}$-adrenoceptor agonist CL316,243 into the left and saline into the

$\leftarrow$

(arrows) immunolabeling in the DM following viral injections into IBAT. 3V, Third ventricle. Low $(\boldsymbol{G})$ and high $(\boldsymbol{H})$ magnification of the microphotographs illustrating single PRV152 (green), single H129 (red), and double PRV152+H129 (arrows) immunolabeling in the $\mathrm{LH}$ following viral injections into IBAT. 3V, Third ventricle; TC, tuber cinereum area. Low $(\boldsymbol{I})$ and high $(\boldsymbol{J})$ magnification of the microphotographs illustrating single PRV152 (green), single H129 (red), and double PRV152 + H129 (arrows) immunolabeling in the PVH following viral injections into IBAT. AHP, Anterior hypothalamic area, posterior part; opt; optic tract. Low $(\boldsymbol{K})$ and high $(\boldsymbol{L})$ magnification of the microphotographs illustrating single PRV152 (green), single H129 (red), and double PRV152 + H129 (arrows) immunolabeling in the MPA following viral injections into IBAT. aca, Anterior commissure. Scale bars: $\boldsymbol{A}, \boldsymbol{C}, \boldsymbol{E}, \boldsymbol{G}, \boldsymbol{I}, \boldsymbol{K}$, $200 \mu \mathrm{m} ; \boldsymbol{B}, \boldsymbol{D}, \boldsymbol{F}, \boldsymbol{H}, \boldsymbol{J}, \boldsymbol{L}, 50 \mu \mathrm{m}$. 


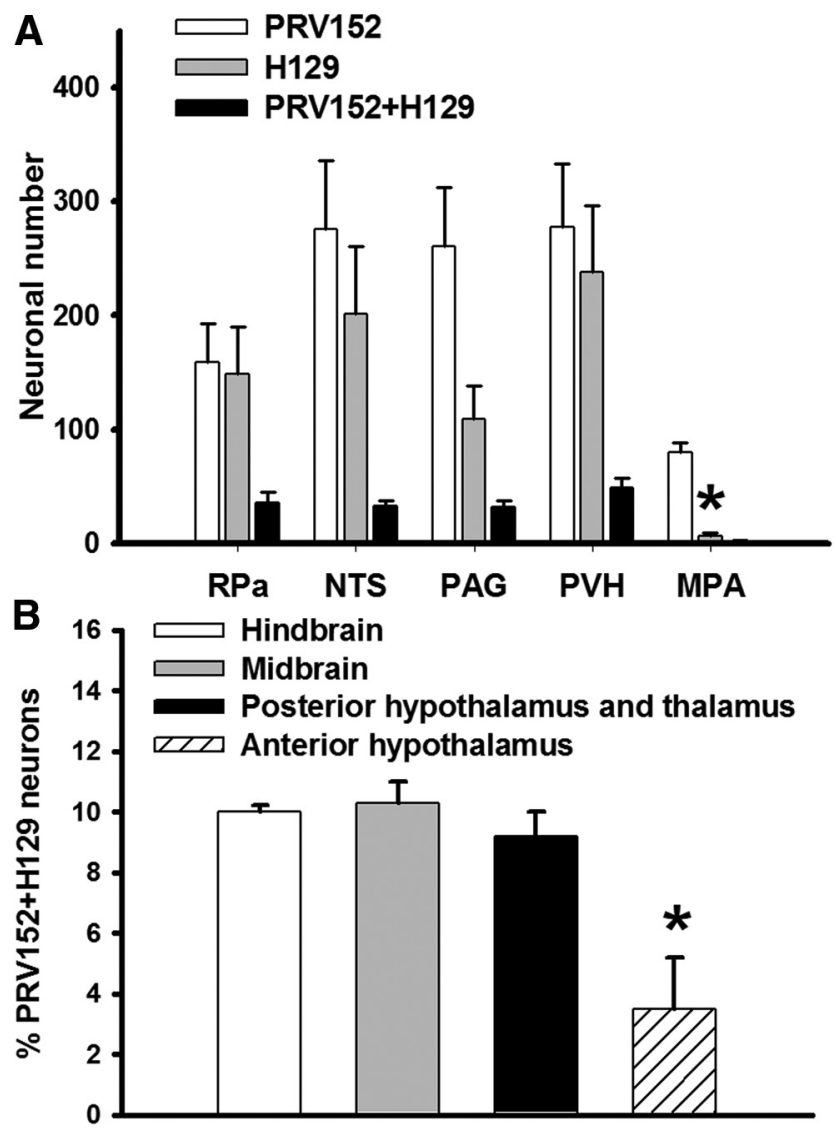

Figure 2. A, Brain areas with highest absolute numbers of PRV152- and H129-IR neurons. Note that the MPA contained predominantly SNS (PRV152) efferent output to IBAT as compared with a SS (H129) afferent input from the same fat pad; $n=5$; ${ }^{*} p<0.05$ versus PRV152. $\boldsymbol{B}$, Percentile quantification of PRV152 and H129 double-labeled (-infected) in the hindbrain, midbrain, posterior hypothalamus and thalamus, and anterior hypothalamus; $n=5$; ${ }^{*} p<0.05$ versus hindbrain, midbrain, and posterior hypothalamus and thalamus.

right IBAT pad. c-Fos immunostaining and FB labeling in the DRG pseudounipolar neurons appeared largely at vertebral C1-T5 levels (Fig. 4A-H). CL316,243 intra-IBAT injections significantly activated C2-C4 DRG neurons ipsilateral to the CL316,243 injections compared with the contralateral control side $\left(F_{(1,17)}=4.51, p<0.05\right.$ for $\mathrm{C} 2 ; F_{(1,23)}=5.63, p<0.05$ for C3; and $F_{(1,23)}=4.85, p<0.05$ for C4; Fig. $\left.4 G, H\right)$. The c-Fos baseline level before the CL316,243 injections was $\sim 4$-fold lower in aforementioned DRG. C4, C5, and T2 DRG contained the highest absolute numbers of FB-labeled neurons innervating IBAT compared with the contralateral side $\left(F_{(1,23)}=9.06, p<0.05\right.$ for $\mathrm{C} 4 ; F_{(1,23)}=9.48, p<0.05$ for $\mathrm{C} 5$; and $F_{(1,23)}=6.36$; $p<0.05$ for T2; Fig. $4 G, H)$. The numbers of FB-labeled DRG neurons were significantly increased at $\mathrm{C} 1-\mathrm{T} 2$ ipsilateral to the $\mathrm{FB}$ injections compared with those of the contralaterally FB-labeled neurons $\left(F_{(1,11)}=10.21, p<0.05\right.$ for $\mathrm{C} 1 ; F_{(1,17)}=8.30, p<0.05$ for $\mathrm{C} 2$; $F_{(1,23)}=30.98, p<0.05$ for $\mathrm{C} 3 ; F_{(1,23)}=9.06, p<0.05$ for $\mathrm{C} 4$; $F_{(1,23)}=9.48, p<0.05$ for $\mathrm{C} 5 ; F_{(1,23)}=4.91, p<0.05$ for $\mathrm{C} 6 ; F_{(1,23)}=4.81, p<0.05$ for $\mathrm{C} 7 ; F_{(1,23)}=5.67, p<0.05$ for $\mathrm{T} 1$; and $F_{(1,23)}=6.36, p<0.05$ for T2; Fig. 4G,H). C3-C6 DRG had significantly more c-Fos + FB colocalized neurons compared with corresponding counter-DRG $\left(F_{(1,23)}=11.66, p<0.05\right.$ for C3; $F_{(1,23)}=12.40, p<0.05$ for $\mathrm{C} 4 ; F_{(1,23)}=9.76, p<0.05$ for $\mathrm{C} 5$; and $F_{(1,23)}=4.66, p<0.05$ for C6; Fig. $\left.4 G, H\right)$.

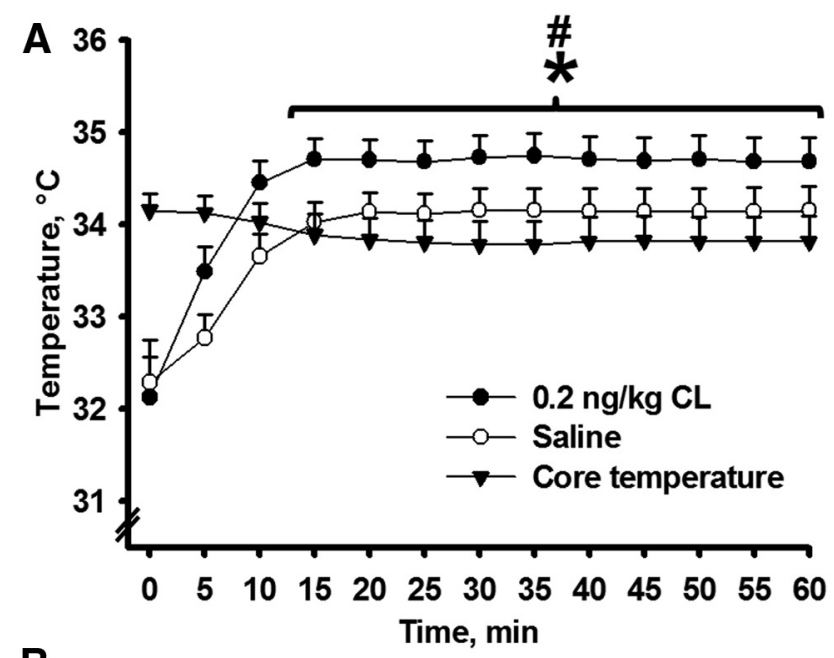

B

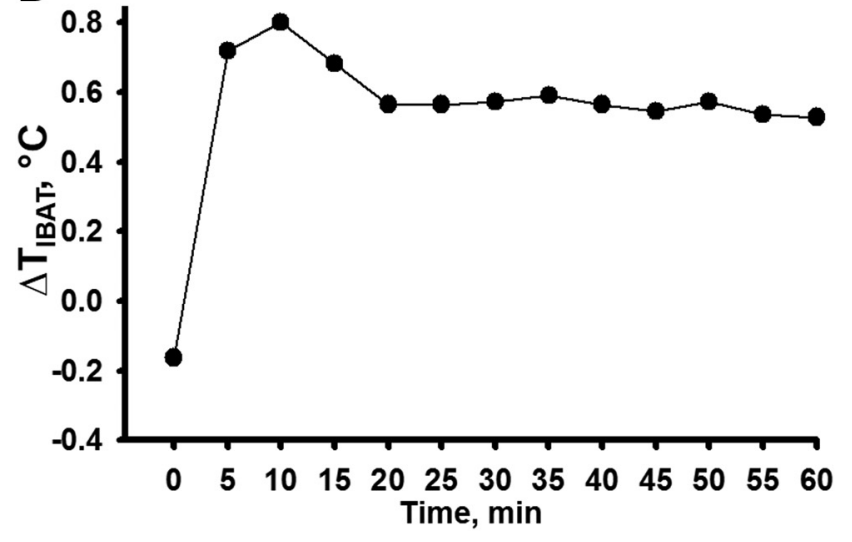

Figure 3. $A$, The activation of IBAT thermogenesis produced by selective $\beta_{3}$-adrenoceptor agonist CL316,243 microinjections intra-left IBAT in comparison with core body temperature and $\mathrm{T}_{\text {IBAT }}$ after saline microinjections intra-right IBAT. $\boldsymbol{B}$, Changes in $\mathrm{T}_{\text {IBAT }}$ after $\mathrm{CL} 316,243$ microinjections intra-left IBAT and saline intra-right IBAT over a 60 min period; $n=12$; ${ }^{*} p<0.05$ versus saline, $\# p<0.05$ versus core body temperature.

Experiment 3: electrophysiological recordings of IBAT afferent nerve activity

Three simultaneous infusions of saline vehicle along the lateralcoronal plane of IBAT resulted in no significant change in the rate of IBAT sensory nerve activity above baseline levels at 10 or 20 min postinfusions. By contrast, three simultaneous intra-IBAT infusions of CL316,243 (0.2 ng/kg; same dose as used for $\mathrm{T}_{\text {IBAT }}$ measures) significantly elevated mean IBAT sensory nerve activity within $10 \min \left(t_{(19)}=10.43, p<0.05\right)$, with peak activity at 20 min postinfusions $\left(t_{(19)}=12.03, p<0.05\right.$; Fig. $\left.4 I\right)$ and a significant interaction between drug and time postinjection $\left(F_{(2,29)}=\right.$ 42.69, $p<0.05$; Fig. $4 I)$.

\section{Discussion}

We report here the presence of crosstalk between the SNS and SS neural innervation of the IBAT evidenced by the colocalization of both PRV152 and H129 neural tract tracers especially predominately in the RPa, NTS, PAG, PVH, and MPA brain regions. In addition, we demonstrated for the first time that intra-IBAT CL316,243-triggered $\beta_{3}$-adrenoceptor stimulation significantly increased $\mathrm{T}_{\text {IBAT }}$ and directly activated IBAT-associated DRG neurons (Fig. 5). Last, intra-IBAT CL316,243-triggered $\beta_{3}$ adrenoceptor stimulation also significantly elevated afferent nerve activity. Collectively, these data provide important insight into the distributed neural system integrating SNS and SS neural 

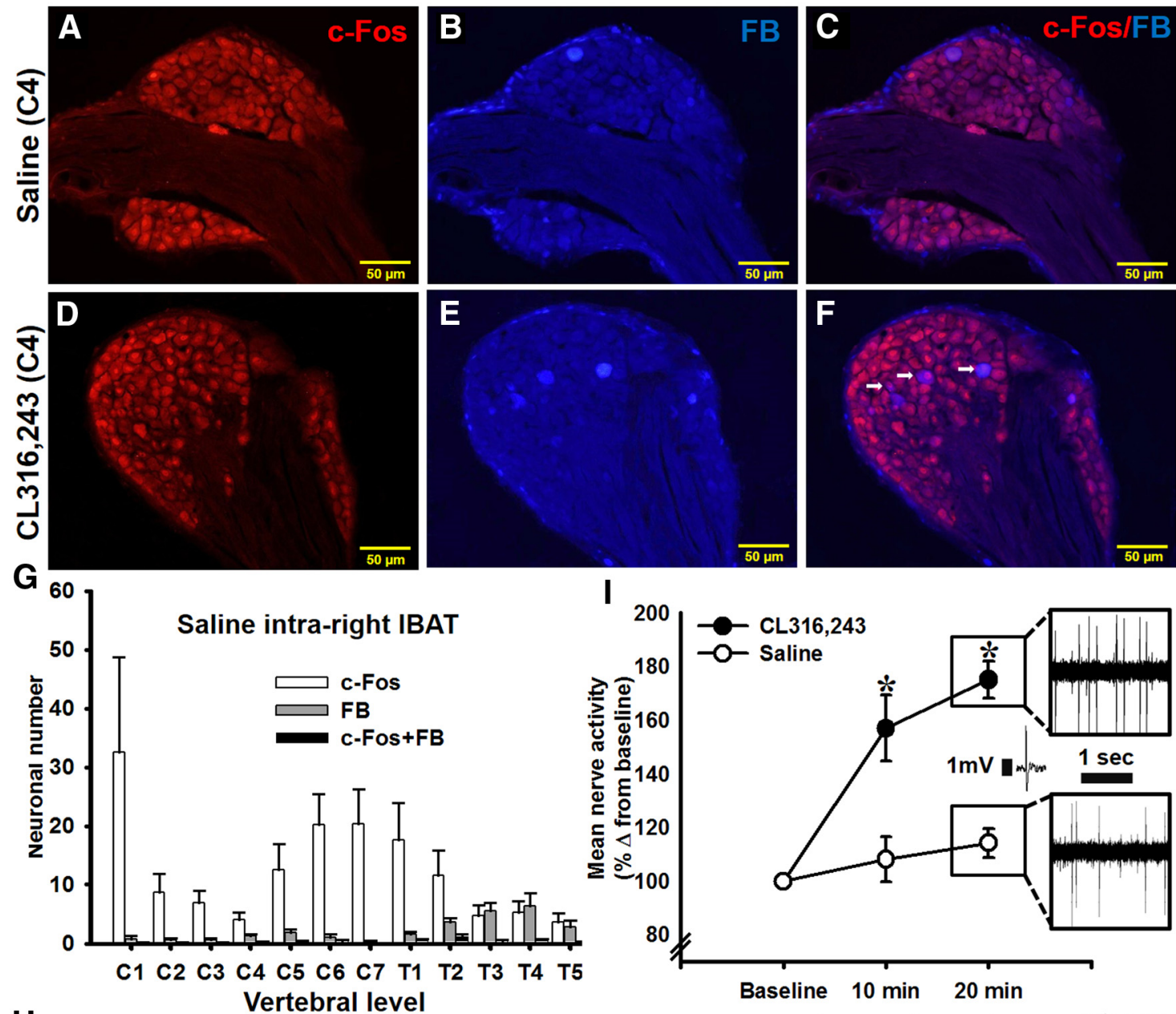

H

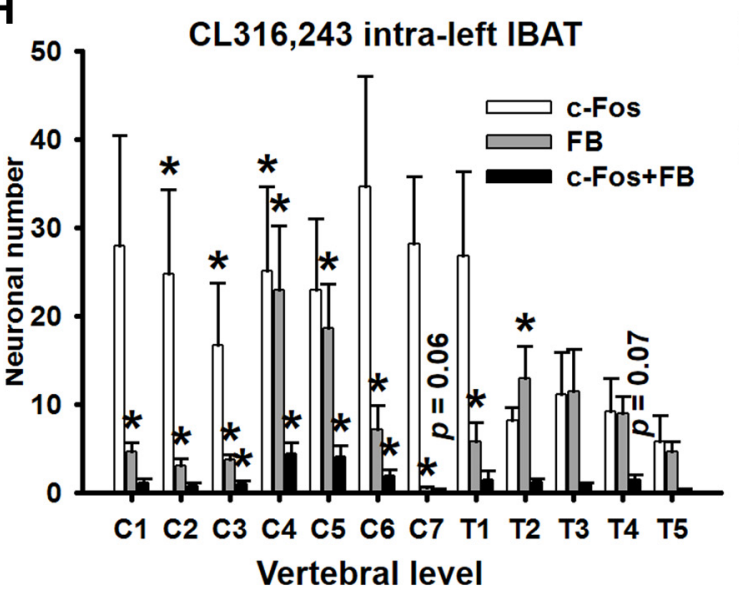

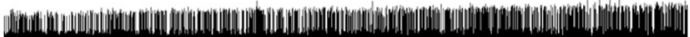

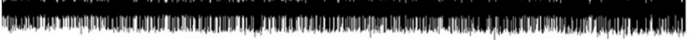
CL316,243 Infusion

$1 \mathrm{~min}$

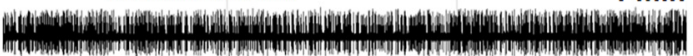

Saline Infusion

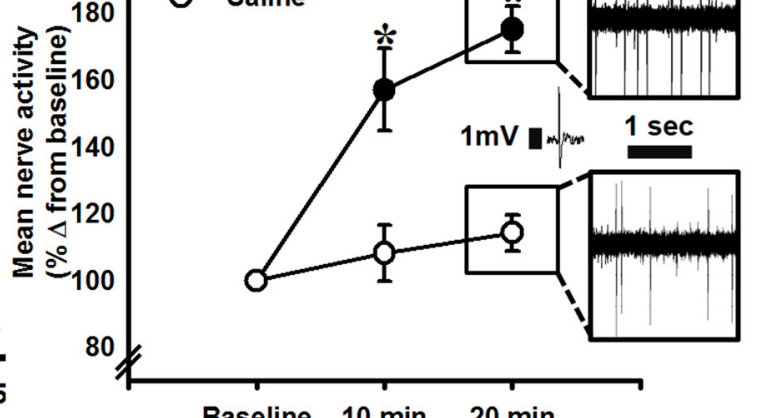

Figure 4. Representative microphotographs of DRG at C4 vertebral level showing c-Fos immunostaining ( $\boldsymbol{A}, \boldsymbol{D})$, FB labeling $(\boldsymbol{B}, \boldsymbol{E})$, and c-Fos + FB colocalization ( $\boldsymbol{C}$, $\boldsymbol{F}$, arrows) after CL316,243 microinjections intra-left and saline intra-right IBAT. Distribution of c-Fos-IR and FB-labeled neurons in IBAT innervating DRG at (1-T4 vertebral levels contralateral $(\boldsymbol{G})$ and ipsilateral $(\boldsymbol{H})$ to CL316,243 microinjections. The total number of positively stained neurons per ganglion can be estimated by multiplying the number per section by $24 ; n=12 ;{ }^{*} p<0.05$ versus saline counter-mate. Scale bar, $50 \mu \mathrm{m}$. I, Mean nerve activity from IBAT afferent fibers before (baseline), at 10 and at 20 min after CL316,243 or saline microinjections; $n=5$ per group. CL316,243-evoked increase in IBAT sensory nerve activity. Bottom, Ten minute sample traces of IBAT afferent fibers before and after infusion of either CL316,243 (top) or saline (bottom); ${ }^{*} p<0.05$ versus saline.

circuits innervating IBAT based on the demonstration of doubly infected neurons (i.e., possible SNS-SS neural feedback loop neurons) and that these IBAT afferents are sensitive to $\beta_{3^{-}}$adrenoceptor stimulation/IBAT thermogenesis.

We found overlap of SNS-SS IBAT-innervating circuits across the neuroaxis. Specifically, the highest overlap of dually infected PRV152+H129 neurons was in the LPGi $(\sim 13 \%), \mathrm{ROb}$ $(\sim 13 \%), \mathrm{MPB}(\sim 13 \%)$, and $\mathrm{RPa}(\sim 13 \%)$ in the hindbrain; LPAG $(\sim 12 \%)$, VLPAG $(\sim 10 \%)$ in the midbrain; and SubZI $(\sim 14 \%)$, PVH $(\sim 11 \%)$, PH $(\sim 11 \%)$, and DM $(\sim 10 \%)$ in the forebrain. All these regions previously were reported to be involved in the control of BAT thermogenesis (Richard et al., 2010; Ulhoa et al., 2013; for review, see Bartness et al., 2010b; Morrison et al., 2014). Note that the number of double-labeled neurons 


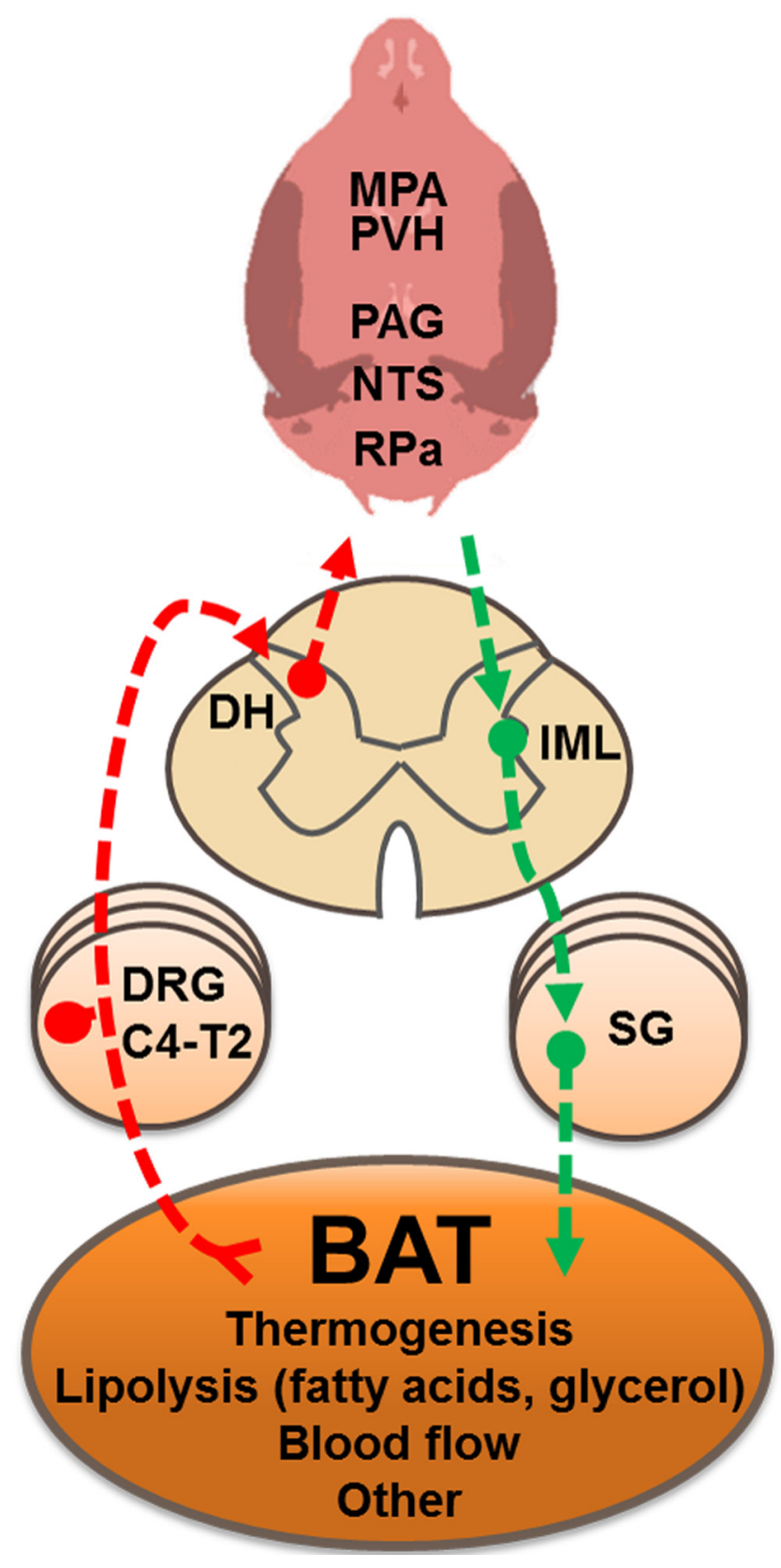

Figure 5. A diaphragmatic representation of the efferent sympathetic (green arrows) and afferent sensory (red arrows) brain-IBAT neural feedback circuit for control of IBAT functions. BAT, brown adipose tissue; (4-T2, Cervical and thoracic vertebral level; DH, dorsal horn; SG, sympathetic ganglia.

likely was underestimated because infection of a neuron with one virus can, in principle, reduce the susceptibility to infection by a second virus (phenomenon of exclusion; (Kim et al., 1999). Due to the unpredictable time interval for each virus to reach each specific area, the neurons on both ascending and descending pathways to IBAT may not have necessarily showed dual infections despite the selection of inoculation/postinoculation time points that optimized the double-virus technique by matching viral progression rates through the neural axis as closely as possible (for review, see Ter Horst, 2000).

Despite predominantly equal SNS and SS representation in many brain regions, several brain regions had differing amounts of SNS efferent output/SS afferent input to and from IBAT. That is, the LPAG, DLPAG, and DR in the midbrain had largely SNS output compared with SS input. The PAG receives afferent fibers not only from the parabrachial nucleus and RPa (Mantyh, 1982), which are critical for the proper thermoregulatory IBAT function (Kobayashi and Osaka, 2003; for review, see Morrison et al., 2014), but also from the spinal cord (Pechura and Liu, 1986). We previously reported that the PAG sends SNS efferents ultimately to WAT in Siberian hamsters (Bamshad et al., 1998; Song et al., 2005b; Nguyen et al., 2014), as did others in laboratory rats (Adler et al., 2012). Moreover, we recently found that the DMPAG was among several other sites with predominantly SNS efferent output to the inguinal WAT (IWAT) compared with SS input from IWAT (Ryu and Bartness, 2014) suggesting differential SNS nodes to different fat pads within the PAG. Regarding the DR, a profound IBAT thermogenic response is triggered with DR electrical stimulation (Dib et al., 1994); thus, it is not surprising to see the DR as a component of the SNS outflow to IBAT with our viral neurocircuit-labeling method.

We found the MPA, MPO, and MnPO were mostly involved with the SNS outflow to, but not the SS inflow from, IBAT and these sites are involved in the IBAT thermoregulatory SNS responses to skin cooling (Nakamura and Morrison, 2008b). This greater SNS outflow from the MPA than SS inflow supports our previous finding of relatively sparse MPA H129-infected neurons from IBAT compared with many other areas (Vaughan and Bartness, 2012), but impressive PRV152-infected neurons (Bamshad et al., 1999; Song et al., 2008; Leitner and Bartness, 2009). Despite the relatively small number of MPA-MPO-MnPO SS circuit neurons, this by no means necessarily lessens its contribution to thermoregulatory signaling from the skin (Nakamura and Morrison, 2008a,b) as the MPA-SS innervation in the present study mainly reflects the SS pathway originating from the IBAT. Because IBAT increases thermogenesis in response to cold exposure in decerebrate rats; however, where most of the midbrain and all of the forebrain are surgically separated from the hindbrain/peripheral nervous systems (Nautiyal et al., 2008), the necessity of SS input to the MPA or other rostral brain sites combined with the presence of PRV152+H129 dually infected neurons in the hindbrain indicates that, unlike some of the models proposed for the BAT SNS thermoregulatory control with the MPA as the "origin" of the descending signals and recipient of the ascending afferent information (Morrison et al., 2012), SS input may crosstalk with central SNS outflow across the neuroaxis including the hindbrain (Nautiyal et al., 2008). Indeed, this notion is supported by thermal sensory inputs to the midbrain and caudal hindbrain implicated in the thermal response to skin cooling and thermal control in general (Uno et al., 2003).

The highest percentage of double-labeled neurons reached $\sim 13.0 \%$ in several hindbrain, midbrain and hypothalamic regions. Compared with more than half of double-labeled SNS-SS feedback neurons in many of the same and other brain areas following injections of PRV152 and H129 into the IWAT (Ryu and Bartness, 2014), this lower rate of double-labeled neurons could reflect a lesser feedback from BAT versus WAT and/or may reflect a lesser number of BAT functions requiring neural feedback compared with WAT. That is, the SNS and SS innervations of BAT may primarily reflect its function in thermogenesis (Fig. 5), whereas a neural feedback for its role in lipid and glucose clearance has not been, to our knowledge, tested and may not require neural feedback (for review, see Cannon and Nedergaard, 2004). By contrast, WAT stores/releases lipid and adipokines and has afferents sensitive to both increases in SNS drive (Bartness et al., 2010a) and to leptin (Murphy et al., 2013), that latter perhaps 
conveying the amounts of stored lipid via this neural conduit (Bartness et al., 2014).

We previously demonstrated that an intact SS innervation of BAT is necessary for normal acute cold exposure-induced IBAT thermogenic increases (Vaughan and Bartness, 2012). To our knowledge, no biochemical signal from BAT responsible for the activation of local SS nerve terminals has been identified at this time. In this regard, we previously reported (Song et al., 2009) that the firing frequency of decentralized SS nerve fibers innervating IWAT was markedly increased when anesthetized hamsters were injected with the glucoprivic agent 2-deoxy-D-glucose known to drive SNS outflow and lipolysis (Brito et al., 2008). Those findings suggest that factors associated with activation of $\beta_{3}$-adrenoceptors, such as fatty acids and glycerol, might activate BAT afferents (Fig. 5). The necessity of lipolysis for the full effect of SNS/NE-induced BAT thermogenesis is demonstrated in brown adipocytes harvested from mice where ablation of all protein kinase A phosphorylation sites on the adipocyte intracellular protein perilipin A result in an abolished NE-induced lipolytic response and these mice exhibit a severely blunted $(\sim 70 \%)$ decrease in NE-induced thermogenesis in vivo (Souza et al., 2007). Other plausible functions for BAT SNS-SS feedback loops include IBAT afferents directly sensing changes in $\mathrm{T}_{\mathrm{IBAT}}$ due to increases in SNS drive and/or to SNS-mediated marked increases in IBAT blood flow seen in cold-exposed Siberian hamsters, and laboratory rats and mice ( $\sim 15$ - to 100 -fold or more; Foster and Frydman, 1978; Puchalski et al., 1987; Baron et al., 2012). Such a role for SS feedback in the control of local blood flow has been repeatedly proposed (Loesch, 2002; Holzer, 2006). Therefore, given that our FB tracing revealed several DRG (C4, C5, and T2) with the highest numbers of projections to IBAT, this may suggest contribution of more than one population of SS nerve bundles with heterogeneous capacity to sense the changes in local temperature, as observed in other organs (Borzan et al., 2005), in blood flow and/or lipolysis-related factors (Fig. 5).

To further understand both the functional and neuroanatomical basis underlying SNS-SS interaction relative to IBAT thermogenesis, we injected CL316,243, a highly selective and potent $\beta_{3}$-adrenoceptor intra-IBAT to determine the vertebral levels at which DRG sensory neurons innervating IBAT are activated by $\beta_{3}$-adrenoceptor stimulation. Our goal was to approximate the naturally occurring stimulation of these receptors by the SNS release of NE parenchymally, but do so specifically to $\beta_{3^{-}}$ adrenoceptors using CL316,243. CL316,243 significantly increased $\mathrm{T}_{\text {IBAT }}$ within $10 \mathrm{~min}$ after injection, activated $\mathrm{C} 2-\mathrm{C} 4$ DRG as evidenced by significantly increased c-Fos immunolabeling in DRG neurons prelabeled with FB ipsilateral to the injection compared with the contralateral control side. Functionally, CL316,243 intra-IBAT injections significantly increased $\mathrm{T}_{\text {IBAT }}$ and afferent nerve activity within the same 20 min time frame.

Collectively, our results show persuasive evidence of the BAT SNS-SS neural feedback loops with a coordinated or multiple redundant controls of thermoregulatory functions. In addition, we demonstrated that sympathetic stimulation directly activates BAT-associated DRG, and hence sensation, perhaps in relation to its thermogenic and/or lipolytic response. Finally, the approach of direct, intra-IBAT injection combined with c-Fos-IR in DRGs and/or electrophysiologic assessment of BAT afferent activity provides a model system with which to determine BAT sensory nerve activators analogous to our study of WAT afferents using the same methodologies (Murphy et al., 2013).

\section{References}

Adler ES, Hollis JH, Clarke IJ, Grattan DR, Oldfield BJ (2012) Neurochemical characterization and sexual dimorphism of projections from the brain to abdominal and subcutaneous white adipose tissue in the rat. J Neurosci 32:15913-15921. CrossRef Medline

Atgié C, Faintrenie G, Carpéne C, Bukowiecki LJ, Géloën A (1998) Effects of chronic treatment with noradrenaline or a specific beta3-adrenergic agonist, CL 316 243, on energy expenditure and epididymal adipocyte lipolytic activity in rat. Comp Biochem Physiol A Mol Integr Physiol 119:629-636. CrossRef Medline

Bamshad M, Aoki VT, Adkison MG, Warren WS, Bartness TJ (1998) Central nervous system origins of the sympathetic nervous system outflow to white adipose tissue. Am J Physiol 275:R291-R299. Medline

Bamshad M, Song CK, Bartness TJ (1999) CNS origins of the sympathetic nervous system outflow to brown adipose tissue. Am J Physiol 276: R1569-R1578. Medline

Baron DM, Clerte M, Brouckaert P, Raher MJ, Flynn AW, Zhang H, Carter EA, Picard MH, Bloch KD, Buys ES, Scherrer-Crosbie M (2012) In vivo noninvasive characterization of brown adipose tissue blood flow by contrast ultrasound in mice. Circ Cardiovasc Imaging 5:652-659. CrossRef Medline

Bartness TJ, Shrestha YB, Vaughan CH, Schwartz GJ, Song CK (2010a) Sensory and sympathetic nervous system control of white adipose tissue lipolysis. Mol Cell Endocrinol 318:34-43. CrossRef Medline

Bartness TJ, Vaughan CH, Song CK (2010b) Sympathetic and sensory innervation of brown adipose tissue. Int J Obes (Lond) 34:S36-S42. CrossRef Medline

Bartness TJ, Liu Y, Shrestha YB, Ryu V (2014) Neural innervation of white adipose tissue and the control of lipolysis. Front Neuroendocrinol 35: 473-493 CrossRef Medline

Borzan J, LaGraize SC, Hawkins DL, Peng YB (2005) Dorsal horn neuron response patterns to graded heat stimuli in the rat. Brain Res 1045:72-79. CrossRef Medline

Brito MN, Brito NA, Baro DJ, Song CK, Bartness TJ (2007) Differential activation of the sympathetic innervation of adipose tissues by melanocortin receptor stimulation. Endocrinology 148:5339-53347. CrossRef Medline

Brito NA, Brito MN, Bartness TJ (2008) Differential sympathetic drive to adipose tissues after food deprivation, cold exposure or glucoprivation. Am J Physiol Regul Integr Comp Physiol 294:R1445-R1452. CrossRef Medline

Cannon B, Nedergaard J (2004) Brown adipose tissue: function and physiological significance. Physiol Rev 84:277-359. CrossRef Medline

De Matteis R, Ricquier D, Cinti S (1998) TH-, NPY-, SP-, and CGRPimmunoreactive nerves in interscapular brown adipose tissue of adult rats acclimated at different temperatures: an immunohistochemical study. J Neurocytol 27:877-886. CrossRef Medline

Dib B, Rompré PP, Amir S, Shizgal P (1994) Thermogenesis in brown adipose tissue is activated by electrical stimulation of the rat dorsal raphe nucleus. Brain Res 650:149-152. CrossRef Medline

Dun NJ, Tang H, Dun SL, Huang R, Dun EC, Wakade AR (1996) Pituitary adenylate cyclase activating polypeptide-immunoreactive sensory neurons innervate rat adrenal medulla. Brain Res 716:11-21. CrossRef Medline

Enquist LW (2002) Exploiting circuit-specific spread of pseudorabies virus in the central nervous system: insights to pathogenesis and circuit tracers. J Infect Dis 186:S209-S214. CrossRef Medline

Foster DO, Frydman ML (1978) Nonshivering thermogenesis in the rat II. Measurements of blood flow with microspheres point to brown adipose tissue as the dominant site of the calorigenesis induced by noradrenaline. Can J Physiol Pharmacol 56:110-122. CrossRef Medline

Funakoshi K, Goris RC, Kadota T, Atobe Y, Nakano M, Kishida R (2003) Prenatal development of peptidergic primary afferent projections to mouse lumbosacral autonomic preganglionic cell columns. Brain Res Dev Brain Res 144:107-119. CrossRef Medline

Gabaldón AM, McDonald RB, Horwitz BA (1998) Effects of age, gender, and senescence on beta-adrenergic responses of isolated F344 rat brown adipocytes in vitro. Am J Physiol 274:E726-E736. Medline

Giordano A, Frontini A, Castellucci M, Cinti S (2004) Presence and distribution of cholinergic nerves in rat mediastinal brown adipose tissue. J Histochem Cytochem 52:923-930. CrossRef Medline

Himms-Hagen J, Cui J, Danforth E Jr, Taatjes DJ, Lang SS, Waters BL, Claus 
TH (1994) Effect of CL-316,243, a thermogenic beta-3 agonist, on energy balance and brown and white adipose tissues in rats. Am J Physiol 266:R1371-R1382. Medline

Hoffman GE, Smith MS, Verbalis JG (1993) c-Fos and related immediate early gene products as markers of activity in neuroendocrine systems. Front Neuroendocrinol 14:173-213. CrossRef Medline

Holzer P (2006) Efferent-like roles of afferent neurons in the gut: blood flow regulation and tissue protection. Auton Neurosci 125:70-75. CrossRef Medline

Horn JP, Stofer WD (1989) Preganglionic and sensory origins of calcitonin gene-related peptide-like and substance P-like immunoreactivities in bullfrog sympathetic ganglia. J Neurosci 9:2543-2561. Medline

Jancśo G, Király E, Jancsó-Gábor A (1980) Direct evidence for an axonal site of action of capsaicin. Naunyn Schmiedebergs Arch Pharmacol 313: 91-94. CrossRef Medline

Jancśo G, Király E, Joó F, Such G, Nagy A (1985) Selective degeneration by capsaicin of a subpopulation of primary sensory neurons in the adult rat. Neurosci Lett 59:209-214. CrossRef Medline

Kim JS, Enquist LW, Card JP (1999) Circuit-specific coinfection of neurons in the rat central nervous system with two pseudorabies virus recombinants. J Virol 73:9521-9531. Medline

Kobayashi A, Osaka T (2003) Involvement of the parabrachial nucleus in thermogenesis induced by environmental cooling in the rat. Pflugers Arch 446:760-765. CrossRef Medline

Leitner C, Bartness TJ (2009) Acute brown adipose tissue temperature response to cold in monosodium glutamate-treated Siberian hamsters. Brain Res 1292:38-51. CrossRef Medline

Loesch A (2002) Perivascular nerves and vascular endothelium: recent advances. Histol Histopathol 17:591-597. Medline

Mantyh PW (1982) The ascending input to the midbrain periaqueductal gray of the primate. J Comp Neurol 211:50-64. CrossRef Medline

Morrison SF, Madden CJ, Tupone D (2012) Central control of brown adipose tissue thermogenesis. Front Endocrinol (Lausanne) 3:00005. CrossRef Medline

Morrison SF, Madden CJ, Tupone D (2014) Central neural regulation of brown adipose tissue thermogenesis and energy expenditure. Cell Metab 19:741-756. CrossRef Medline

Murphy KT, Schwartz GJ, Nguyen NL, Mendez JM, Ryu V, Bartness TJ (2013) Leptin-sensitive sensory nerves innervate white fat. Am J Physiol Endocrinol Metab 304:E1338-E1347. CrossRef Medline

Nakamura K, Morrison SF (2008a) A thermosensory pathway that controls body temperature. Nat Neurosci 11:62-71. CrossRef Medline

Nakamura K, Morrison SF (2008b) Preoptic mechanism for cold-defensive responses to skin cooling. J Physiol 586:2611-2620. CrossRef Medline

Nautiyal KM, Dailey M, Brito N, Brito MN, Harris RB, Bartness TJ, Grill HJ (2008) Energetic responses to cold temperatures in rats lacking forebrain-caudal brainstem connections. Am J Physiol Regul Integr Comp Physiol 295:R789-798. CrossRef Medline

Nguyen NL, Randall J, Banfield BW, Bartness TJ (2014) Central sympathetic innervations to visceral and subcutaneous white adipose tissue. Am J Physiol Regul Integr Comp Physiol 306:R375-R386. CrossRef Medline

Norman D, Mukherjee S, Symons D, Jung RT, Lever JD (1988) Neuropeptides in interscapular and perirenal brown adipose tissue in the rat: a plurality of innervation. J Neurocytol 17:305-311. CrossRef Medline

Oldfield BJ, Giles ME, Watson A, Anderson C, Colvill LM, McKinley MJ (2002) The neurochemical characterisation of hypothalamic pathways projecting polysynaptically to brown adipose tissue in the rat. Neuroscience 110:515-526. CrossRef Medline

Paxinos G, Franklin KBJ (2007) The mouse brain in stereotaxic coordinates. New York: Academic.

Pechura CM, Liu RP (1986) Spinal neurons which project to the periaqueductal gray and the medullary reticular formation via axon collaterals: a doublelabel fluorescence study in the rat. Brain Res 374:357-361. CrossRef Medline

Peng YW, Kohno J, Shinoda K, Kawai Y, Ono K, Jiang WH, Shiotani Y (1989) Interaction between cholinergic neurons and substance $\mathrm{P}$ or calcitonin gene-related peptide terminals of the rat sacral intermediolateral nucleus: double immunostaining at the light and electron microscopic levels. J Comp Neurol 285:1-8. CrossRef Medline
Puchalski W, Böckler H, Heldmaier G, Langefeld M (1987) Organ blood flow and brown adipose tissue oxygen consumption during noradrenalineinduced nonshivering thermogenesis in the Djungarian hamster. J Exp Zool 242:263-271. CrossRef Medline

Reuss S (1993) Calcitonin gene-related peptide-like immunoreactivity in spinal cord and superior cervical ganglion of the Djungarian hamster (Phodopus sungorus). J Chem Neuroanat 6:343-350. CrossRef Medline

Richard D, Picard F (2011) Brown fat biology and thermogenesis. Front Biosci (Landmark Ed) 16:1233-1260. CrossRef Medline

Richard D, Carpentier AC, Dore G, Ouellet V, Picard F (2010) Determinants of brown adipocyte development and thermogenesis. Int J Obes (Lond) 34:S59-S66. CrossRef Medline

Ryu V, Bartness TJ (2014) Short and long sympathetic-sensory feedback loops in white fat. Am J Physiol Regul Integr Comp Physiol 306:R886R900. CrossRef Medline

Schäfer MK, Eiden LE, Weihe E (1998) Cholinergic neurons and terminal fields revealed by immunohistochemistry for the vesicular acetylcholine transporter: II. The peripheral nervous system. Neuroscience 84:361-376. CrossRef Medline

Song CK, Enquist LW, Bartness TJ (2005a) New developments in tracing neural circuits with herpesviruses. Virus Res 111:235-249. CrossRef Medline

Song CK, Jackson RM, Harris RB, Richard D, Bartness TJ (2005b) Melanocortin-4 receptor mRNA is expressed in sympathetic nervous system outflow neurons to white adipose tissue. Am J Physiol Regul Integr Comp Physiol 289:R1467-R1476. CrossRef Medline

Song CK, Vaughan CH, Keen-Rhinehart E, Harris RB, Richard D, Bartness T] (2008) Melanocortin-4 receptor mRNA expressed in sympathetic outflow neurons to brown adipose tissue: neuroanatomical and functional evidence. Am J Physiol Regul Integr Comp Physiol 295:R417-R428. CrossRef Medline

Song CK, Schwartz GJ, Bartness TJ (2009) Anterograde transneuronal viral tract tracing reveals central sensory circuits from white adipose tissue. Am J Physiol Regul Integr Comp Physiol 296:R501-R511. CrossRef Medline

Souza SC, Christoffolete MA, Ribeiro MO, Miyoshi H, Strissel KJ, Stancheva ZS, Rogers NH, D'Eon TM, Perfield JW 2nd, Imachi H, Obin MS, Bianco AC, Greenberg AS (2007) Perilipin regulates the thermogenic actions of norepinephrine in brown adipose tissue. J Lipid Res 48:1273-1279. CrossRef Medline

Tan CK, Tang FR, Ling EA (1996) Ultrastructural localization of substance P-like immunoreactivity in the intermediolateral column of spontaneously hypertensive rats and Wistar-Kyoto rats. Histol Histopathol 11: 303-311. Medline

Ter Horst GJ (2000) Transneuronal retrograde dual viral labelling of central autonomic circuitry: possibilities and pitfalls. Auton Neurosci 83:134139. CrossRef Medline

Ulhoa MA, da Silva NF, Pires JG, Futuro Neto Hde A (2013) Raphe obscurus neurons participate in thermoregulation in rats. Arq Neuropsiquiatr 71:249-253. CrossRef Medline

Uno T, Roth J, Shibata M (2003) Influence of the hypothalamus on the midbrain tonic inhibitory mechanism on metabolic heat production in rats. Brain Res Bull 61:129-138. CrossRef Medline

Vaughan CH, Bartness TJ (2012) Anterograde transneuronal viral tract tracing reveals central sensory circuits from brown fat and sensory denervation alters its thermogenic responses. Am J Physiol Regul Integr Comp Physiol 302:R1049-R1058. CrossRef Medline

Vaughan CH, Shrestha YB, Bartness TJ (2011) Characterization of a novel melanocortin receptor-containing node in the SNS outflow circuitry to brown adipose tissue involved in thermogenesis. Brain Res 1411:17-27. CrossRef Medline

Yamamoto K, Senba E, Matsunaga T, Tohyama M (1989) Calcitonin generelated peptide containing sympathetic preganglionic and sensory neurons projecting to the superior cervical ganglion of the rat. Brain Res 487:158-164. CrossRef Medline

Zhao J, Unelius L, Bengtsson T, Cannon B, Nedergaard J (1994) Coexisting beta-adrenoceptor subtypes: significance for thermogenic process in brown fat cells. Am J Physiol 267:C969-C979. Medline 